\title{
A Morphometric and Statistical Study for Determination of Sex from Certain Bony Pelvic Parameters in Assiut Governorate by Using Plain X-Ray Films Sherif Fahmy Mahmoud, Nagy Mohammed Al Fadaly, Huda Abdel Karim Abdel Samie, Gamal El Din Ibrahim Abdel Halim, Abdel Rahman Zaki Abdel Rahman* \\ Department of Forensic Medicine and Toxicology, Faculty of Medicine, Al-Azhar University \\ *Correspondence author: Abdel Rahman Zaki Abdel Rahman, Mobile: (+20) 0114638 5665, \\ E-mail: zaky.abdelrahman@yahoo.com
}

\section{ABSTRACT}

Background: The identification of sex from human remains is of fundamental importance in forensic medicine and anthropology, especially in criminal investigations as well as in the identification of missing persons and in attempts at reconstructing the lives of ancient populations.

Objective: The aim of this study was to assess specific pelvic parameters (Human sacrum and subpubic angle measurements) in Assiut Governorate population by using plain x-ray films.

Patients and methods: The study was conducted on 500 plain x-ray films, which were obtained and collected from the Radiology Department- Al-Azhar Faculty of Medicine (Assiut branch), out of which, 250 were males and 250 were females in the age group of 25-70 years belonging to Assiut population to assess the sacral and subpubic angle measurements.

Results: Statistically significant increase in the length of sacrum in males compared to females. The sacral length in males varied from 86-120 mm with the mean value of $100.06 \pm 9.00 \mathrm{~mm}$, while the sacral length in females varied from 78-120 mm with the mean value of $93.00 \pm 9.46 \mathrm{~mm}$.

Conclusion: The present study concluded that the subpubic angle is the best criterion for sex determination of pelvis. It was found that $66.4 \%$ of males' bones and $58.4 \%$ of females' bones could be identified by using subpubic angle alone.

Keywords: Sex, Pelvic parameters, Human, Plain x-ray films.

\section{INTRODUCTION}

Identification of sex based on morphological marks is subjective and likely to be inaccurate, but methods based on measurements and morphometry are accurate and can be used in determination of sex ${ }^{(\mathbf{1})}$.

It has been established that socio-environmental factors (e.g. nutrition, food, climate, pathologies, etc.) influence the development and in turn the appearance of bones. Numerous studies have demonstrated that skeletal characteristics differ in each population and have emphasized the need for population-specific osteometric standards for sex determination ${ }^{(2)}$. Sexual dimorphism refers to those differences in size, structure and appearance between male and female at an equal age ${ }^{(3)}$. Determination of sex is an integral part and first step in the development of the biological profile in human osteology. Sex determination is necessary to make age, ancestry and stature estimations (4). Gender determination of skeleton remains a part of archaeological and medicolegal examinations. The methods vary and depend on the available bones and their condition. The only method that can give a totally accurate result is the DNA technique, but in many cases, for several reasons, it cannot be used ${ }^{(5)}$. When the entire adult skeleton is available for analysis, sex can be determined up to $100 \%$ accuracy, but in cases of mass disasters where usually fragmented bones are found, sex determination with $100 \%$ accuracy is not possible and it depends largely on the available parts of skeleton ${ }^{(6)}$.

Identification of sex of an individual is one of the most important aspects of medicolegal cases and anthropological research. Availability of simple, economical, quick and accurate modalities can drastically reduce the time taken in the identification of individuals, thus shortening the legalities associated with the same. Usually, skull is either used alone or in conjunction with pelvis to determine sex of unknown skeletal remains ${ }^{(7)}$. The pelvis is the most reliable source for sex dimorphism among human bones, but when a complete pelvis is absent in such cases, other bones can be an important aid in identification ${ }^{(8)}$. The different parts of the bony pelvis had been studied to find out these differences in both sexes and their significance in sex identification. One of the most parameters used is the shape and the contour of the articulated pelvis regarding the shape and diameters of the pelvic inlet and outlet ${ }^{(9)}$.

Sex-dependent differences have been noted in the pelvic bone anatomy, and so it follows that differences exist in the male and female sacrum ${ }^{(10)}$. The sacrum can be used for sexual dimorphism as in anthropological work. The knowledge of sacral index discriminates function analysis and demarking point (DP), which is also essential in medicolegal practice for age, sex and race determination of an individual. The well known method for determination of male or female type from the sacrum has been called the "Sacral Index". Sacral Index is one of the important indices used to identify the gender of the bone which is computed by multiplying the width of the sacrum by 100 and dividing it by the height (length) of the sacrum. In women the breadth of the sacrum as a rule is longer than the height when compared to men. Therefore, the aacral index also differs between men and women and hence it is used as a parameter to identify sex ${ }^{\mathbf{( 1 1 )}}$.

female has a larger sub-pubic angle compared to that of a man and this is obviously indicative of child 
bearing requirements in the female that are not required in the male species. The male's sub-pubic angle or area is less than ninety degrees whilst the female's is more ${ }^{(\mathbf{1 2})}$.

Radiography can contribute to gender determination by providing precise dimensions for which special formulas can be applied ${ }^{(\mathbf{1 3})}$. Radiography is a less invasive method, which can be employed in both living and dead individuals ${ }^{(\mathbf{1 4})}$.

\section{AIM OF THE WORK}

\section{General Objectives:}

The aim of this study was to assess specific pelvic parameters (Human sacrum and subpubic angle measurements) in Assiut Governorate population by using plain x-ray films.

\section{Specific Objectives:}

This study is carried out to:

1- Determine the average sacrum and subpubic angle measurements in Assiut Governorate males.

2- Determine the average sacrum and subpubic angle measurements in Assiut Governorate females.

3- Identify if there is any significant difference in sacrum and sub-pubic angle measurements in Assiut Governorate male and female subjects.

4- Identify if there was any relationship between the sacrum and sub-pubic angle measurements in Assiut Governorate population with that of other populations established, documented and published.

\section{MATERIALS AND METHODS}

Study Design: This is an observational descriptive crosssectional hospital based study, which was carried out in the Department of Forensic Medicine and Clinical Toxicology, Al-Azhar Faculty of Medicine in collaboration with the Department of Radiology, AlAzhar Faculty of Medicine (Assiut branch).

Study Area: This study was conducted at the Radiology Department of Al-Azhar University Hospital in Assiut.

Sample Size: The study was conducted on 500 plain $\mathrm{x}$ ray films, which were obtained and collected from the Radiology Department, Al-Azhar Faculty of Medicine (Assiut branch). 250 were males and 250 were females in the age group of 25-70 years belonging to Assiut population.

Inclusion Criteria: All pelvic plain x-ray films, which were used must be clearly showing the sacrum and subpubic angle.

\section{Exclusion criteria:}

- All plain X-ray films that showed any pelvic and lower limb fractures or pathological disorders.

- All plain X-ray films with inappropriate alignment or non satisfactory.
Materials
1- A pencil.
2- X-ray viewing box.
3- A protractor.
4- A ruler.

\section{Methods}

The identification of films was on the basis of sex, age and place of origin. The plain x-ray films were taken with routine distance of $92 \mathrm{~cm}$ in the anterior posterior view. The plain $\mathrm{x}$-ray films showed the complete pelvis. The methods used for these findings were that of Wilder ${ }^{(15)}$, Davivongs ${ }^{(16)}$ and Flander ${ }^{(17)}$ except otherwise stated. Measurements in millimeter (mm) were taken using a ruler and pencils (where necessary) with the plain $\mathrm{X}$-ray films placed on a viewing box.

The following parameters were examined and measured: 1. Maximum length or Wilder's mid-ventral straight length. This is the distance between the sacral promontory and the junction of the sacrum with coccyx.

2. Maximum breadth or Wilder's anterior straight length. This is the distance between the alae of sacrum.

3. The sacral index was calculated as: Maximum breadth x 100/Maximum length. The five hundred sacra that were measured all possessed 5 sacral segments and did not show any form of developmental anomaly or disorder.

4. The subpubic angle was measured from the plain $\mathrm{x}$-ray films that had the pelvis placed such that the ischial tuberosities and the inferior end of the coccyx were resting on a horizontal surface. The lower border of the inferior rami of the pubis had straight medial borders and these were considered to be the sides of the angle. The angle was measured by placing each radiograph on an $\mathrm{x}$-ray viewing box for clear visualization. A point was chosen at the inferior midline of inter-pubic disc and two tangential lines drawn at the inferior border of the pubic rami intersecting at an angle of the chosen point. A protractor was placed over the intersection of these two lines and the angle was measured.

For identification of male sacrum, the demarking point (D.P.) of a particular measurement was more than 3 S.D. of mean value for female. For identification of female sacrum, the D.P. of same measurement was less than 3 S.D. of mean value for male ${ }^{(\mathbf{1 8})}$.

\section{Ethical Considerations:}

- Consent of the Radiology Department of Al Azhar University Hospital in Assiut was obtained preceding the data collection.

- Approval from Ethics Committee at Al-Azhar University was obtained.

Period of study: It was prepared and suggested to be one year.

\section{Statistical analysis}

Recorded data were analyzed using the statistical package for social sciences, version 20.0 (SPSS Inc., Chicago, Illinois, USA). Quantitative data were expressed as mean \pm standard deviation (SD). Qualitative data were expressed as frequency and percentage. 


\section{The following tests were done:}

- Independent-samples t-test of significance was used when comparing between two means.

- Chi-square $\left(\mathrm{x}^{2}\right)$ test of significance was used in order to compare proportions between two qualitative parameters.

- The confidence interval was set to $95 \%$ and the margin of error accepted was set to 5\%. The p-value was considered significant as the following:

- Probability (P-value)

$\mathrm{P}$-value $<0.05$ was considered significant.

$\mathrm{P}$-value $<0.001$ was considered as highly significant.

$\mathrm{P}$-value $>0.05$ was considered insignificant.

\section{RESULTS}

A morphometric and statistical study for determination of sex from certain bony pelvic parameters in Assiut governorate by using plain x-ray films.

Table (1): Descriptive data

\begin{tabular}{|l|c|c|}
\hline \multicolumn{1}{|c|}{ Sex } & No. & \% \\
\hline Males & 250 & 50.0 \\
\hline Females & 250 & 50.0 \\
\hline
\end{tabular}

The total number of cases of the present study was 500 cases of them 250 males, which represented $50 \%$ of the total number of cases and 250 females which represented $50 \%$ of the total number of cases as shown in table (1).

Table (2): Distributed age according to sex

\begin{tabular}{|l|c|c|}
\hline \multirow{2}{*}{\multicolumn{1}{|c|}{ Age }} & \multicolumn{2}{c|}{ Sex } \\
\cline { 2 - 3 } & Male $(\mathbf{n = 2 5 0})$ & Female $(\mathbf{n = 2 5 0})$ \\
\hline Rang & $25-70 \mathrm{yr}$. & $25-70 \mathrm{yr}$. \\
\hline Mean \pm SD & $46.0 \pm 15.62 \mathrm{yr}$ & $46.66 \pm 14.69 \mathrm{yr}$. \\
\hline
\end{tabular}

Table (2) showed that the total number of cases was (500 cases) with age range from 25-70 years, of them 250 males with a mean value of $46.0 \pm 15.62$ years and 250 females with a mean value of $46.66 \pm 14.69$ years.

Table (3): Comparison between males and females according to mean subpubic angles

\begin{tabular}{|c|c|c|c|c|c|}
\hline \multirow{2}{*}{$\begin{array}{l}\text { Sub- } \\
\text { pubic } \\
\text { angle }\end{array}$} & \multicolumn{2}{|r|}{ Sex } & \multirow[b]{2}{*}{$\begin{array}{c}\mathrm{Z} . \\
\text { value }\end{array}$} & \multirow[b]{2}{*}{$\begin{array}{c}P- \\
\text { value }\end{array}$} & \multirow{2}{*}{$\begin{array}{r}\text { Overall } \\
\text { mean } \\
\text { angle }\end{array}$} \\
\hline & $\begin{array}{c}\text { Male } \\
(\mathbf{n}=\mathbf{2 5 0})\end{array}$ & $\begin{array}{l}\text { Female } \\
(\mathbf{n}=250)\end{array}$ & & & \\
\hline Range & $67^{\circ}-119^{\circ}$ & $100^{\circ}-1$ & & & \\
\hline $\begin{array}{l}\text { Mean } \pm \\
\text { SD }\end{array}$ & $\begin{array}{c}94.76^{\circ} \pm \\
11.99\end{array}$ & $\begin{array}{c}133.20^{\circ} \pm \\
10.68\end{array}$ & 06 & (H.S) & \\
\hline
\end{tabular}

(N.B.): H.S means: Highly significant.

Overall mean angle means: The race was assigned from the overall mean for this racial group.

Z. value means: Statistical comparison between males and females (Z. test).

The sub-pubic angles ranged from $67^{\circ}$ to $119^{\circ}$ in Egyptian males and from $100^{\circ}$ to $155^{\circ}$ in Egyptian females of the present study. Females have a wider angles with a mean value of $133.20^{\circ} \pm 10.68$ than males, which represent a mean value of $94.76^{\circ} \pm 11.99$. The subpubic angle showed a highly significant difference between both sexes $(\mathrm{P}<0.001)$. The overall mean angle for the Egyptians of the present study was $113.98^{\circ}$ as shown in table (3).

Table (4): Measurements in ( $\mathrm{mm}$ ) and statistical analysis of the sacral length in 500 pelvic plain X-ray films (250 males and 250 females)

\begin{tabular}{|c|c|c|c|c|c|}
\hline Sacral length & Male & Female & $\begin{array}{c}\text { Overal } \\
\text { mean } \\
\text { length }\end{array}$ & $\begin{array}{r}\mathrm{Z} \\
\text { value }\end{array}$ & $\begin{array}{r}P \\
\text { value }\end{array}$ \\
\hline Number & 250 & 250 & \multirow{9}{*}{$\begin{array}{c}96.53 \\
\mathrm{~mm}\end{array}$} & \multirow{9}{*}{8.301} & \multirow{9}{*}{$1 \quad \begin{array}{l}0.001 \\
* * \\
(\mathrm{H} . \mathrm{S})\end{array}$} \\
\hline Mean value & $\begin{array}{r}100.06 \\
\mathrm{~mm}\end{array}$ & $\begin{array}{r}93.00 \\
\mathrm{~mm}\end{array}$ & & & \\
\hline Actual range & $\begin{array}{r}86 \mathrm{~mm}- \\
120 \mathrm{~mm}\end{array}$ & $\begin{array}{r}78 \mathrm{~mm}- \\
120 \mathrm{~mm}\end{array}$ & & & \\
\hline $\begin{array}{l}\text { Standard } \\
\text { deviation (SD) }\end{array}$ & 9.00 & 9.46 & & & \\
\hline $\begin{array}{l}\text { Identification } \\
\text { point (IP) }\end{array}$ & $\begin{array}{r}<78 \\
\mathrm{~mm}\end{array}$ & $\begin{array}{r}>120 \\
\mathrm{~mm} \\
\end{array}$ & & & \\
\hline $\begin{array}{l}\text { Percentage } \\
\text { identification } \\
\text { point }\end{array}$ & $0 \%$ & $0 \%$ & & & \\
\hline $\begin{array}{l}\text { Calculated } \\
\text { range } \\
(\text { mean } \pm 3 S D)\end{array}$ & $\begin{array}{r}73.06 \\
\mathrm{~mm}- \\
127.06 \\
\mathrm{~mm}\end{array}$ & $\begin{array}{r}64.62 \\
\mathrm{~mm}- \\
121 . \\
38 \mathrm{~mm}\end{array}$ & & & \\
\hline $\begin{array}{l}\text { Demarking point } \\
\text { (DP) }\end{array}$ & $\begin{array}{c}>121.38 \\
\mathrm{~mm}\end{array}$ & $\begin{array}{r}<73.06 \\
\mathrm{~mm} \\
\end{array}$ & & & \\
\hline $\begin{array}{l}\text { Percentage } \\
\text { demarking point }\end{array}$ & $0 \%$ & $0 \%$ & & & \\
\hline
\end{tabular}

(N.B.): H.S means: Highly significant.

Overall mean length means: The race was assigned from the overall mean for this racial group.

Z. value means: Statistical comparison between males and females (Z. test).

Table (4) showed that the mean length of the sacrum was greater in males than in females with a highly significant difference between both sexes $(\mathrm{P}<0.001)$. The overall mean length of the Egyptians in the present study was $96.53 \mathrm{~mm}$.

The length of the sacrum varied from $86 \mathrm{~mm}-$ $120 \mathrm{~mm}$ with a mean value of $100.06 \pm 9.00 \mathrm{~mm}$ in males and from $78 \mathrm{~mm}-120 \mathrm{~mm}$ with a mean value of $93.00 \pm$ $9.46 \mathrm{~mm}$ in females. The identification point which represented the low or high value got from the actual range of the values measured from male and female sacra were $<78 \mathrm{~mm}$ for males and $>120 \mathrm{~mm}$ for females. The demarking point is more useful in sex determination, which was based on the limiting points of the calculated range by using the formula (mean $\pm 3 \mathrm{SD}$ ), i.e. the demarking point for males which was the minimum calculated range for females which represented $<64.62$ $\mathrm{mm}$, while in females was the maximum calculated range for males which represented $>127.06 \mathrm{~mm}$. 
ejhm.journals.ekb.eg

Table (5): Measurements in (mm) and statistical analysis of the sacral width in 500 pelvic plain X-ray films (250 males and 250 females)

\begin{tabular}{|c|c|c|c|c|c|}
\hline Sacral width & Male & Female & $\begin{array}{c}\begin{array}{c}\text { Overall mea } \\
\text { width }\end{array} \\
\end{array}$ & $Z$ value & $P$ value \\
\hline Number & 250 & 250 & \multirow{9}{*}{$112.50 \mathrm{~mm}$} & \multirow{9}{*}{-2.773} & \multirow{9}{*}{$\begin{array}{c}0.019 * \\
(\mathrm{~S})\end{array}$} \\
\hline Mean value & $113.51 \mathrm{~mm}$ & $111.48 \mathrm{~mm}$ & & & \\
\hline Actual range & $95.5 \mathrm{~mm}-135 \mathrm{~mm}$ & $91 \mathrm{~mm}-139 \mathrm{~mm}$ & & & \\
\hline Standard deviation (SD) & 8.97 & 10.31 & & & \\
\hline Identification point (IP) & $<91 \mathrm{~mm}$ & $>135 \mathrm{~mm}$ & & & \\
\hline Percentage identification point & $0 \%$ & $2 \%$ & & & \\
\hline Calculated range (mean $\pm 3 \mathrm{SD})$ & $86.6 \mathrm{~mm}-140.42 \mathrm{mr}$ & $80.55 \mathrm{~mm}-142.41 \mathrm{mr}$ & & & \\
\hline Demarking point (DP) & $>142.41 \mathrm{~mm}$ & $<86.6 \mathrm{~mm}$ & & & \\
\hline Percentage demarking point & $0 \%$ & $0 \%$ & & & \\
\hline
\end{tabular}

(N.B.): S means: Significant.

Overall mean width means: The race was assigned from the overall mean for this racial group.

Z. value means: Statistical comparison between males and females (Z. test).

Table (5) showed that the mean width of the sacra was greater in females than in males with a significant difference between both sexes $(\mathrm{P}=0.019)$. The overall mean width in Egyptians in the present study was $112.50 \mathrm{~mm}$. The width of the sacra varied from $95.5 \mathrm{~mm}-135 \mathrm{~mm}$ with a mean value of $113.51 \pm 8.97 \mathrm{~mm}$ in males and from $91 \mathrm{~mm}-139 \mathrm{~mm}$ with a mean value of $111.48 \pm 10.31 \mathrm{~mm}$ in females. The identification points were $<91 \mathrm{~mm}$ for males and $>135 \mathrm{~mm}$ for females. The demarking points were $>140.42 \mathrm{~mm}$ for females and $<80.55 \mathrm{~mm}$ for males.

Table (6): Measurements in (mm) and statistical analysis of the sacral index in500 pelvic plain X-ray films (250 males and 250 females)

\begin{tabular}{|c|c|c|c|c|c|}
\hline Sacral index & Male & Female & $\begin{array}{c}\text { Overall } \\
\text { mean indes }\end{array}$ & $\begin{array}{c}\mathbf{Z} \\
\text { value }\end{array}$ & $\begin{array}{c}\mathbf{P} \\
\text { value }\end{array}$ \\
\hline Number & 250 & 250 & \multirow{9}{*}{$117.12 \mathrm{~mm}$} & \multirow{9}{*}{$8 . \overline{710}$} & \multirow{9}{*}{$\begin{array}{c}<0.001 \\
* * \\
(\mathrm{H} . \mathrm{S})\end{array}$} \\
\hline Mean value & $113.61 \mathrm{~mm}$ & $120.63 \mathrm{~mm}$ & & & \\
\hline Actual range & $100.92 \mathrm{~mm}-145.11 \mathrm{mr}$ & $100.99 \mathrm{~mm}-163.13 \mathrm{mr}$ & & & \\
\hline Standard deviation (SD) & 8.08 & 10.03 & & & \\
\hline Identification point (IP) & $<100.99 \mathrm{~mm}$ & $>145.11 \mathrm{~mm}$ & & & \\
\hline Percentage identification point & $0.8 \%$ & $3.2 \%$ & & & \\
\hline Calculated range (mean $\pm 3 \mathrm{SD})$ & $89.37 \mathrm{~mm}-137.85 \mathrm{~mm}$ & $90.54 \mathrm{~mm}-150.72 \mathrm{~mm}$ & & & \\
\hline Demarking point (DP) & $<90.54 \mathrm{~mm}$ & $>137.85 \mathrm{~mm}$ & & & \\
\hline Percentage demarking point & $0 \%$ & $5.2 \%$ & & & \\
\hline
\end{tabular}

(N.B.): H.S means: Highly significant.

Overall mean index means: The race was assigned from the overall mean for this racial group.

Z. value means: Statistical comparison between males and females (Z. test).

The mean value of the sacral index was higher in females than in males with a highly significant difference $(p$ $<0.001)$. The overall mean index in Egyptians in the present study was $117.12 \mathrm{~mm}$. The sacral index varied from $100.92-145.11 \mathrm{~mm}$ with a mean value of $113.61 \pm 8.08 \mathrm{~mm}$ in males and from $100.99-163.13 \mathrm{~mm}$ variance with a mean value of $120.63 \pm 10.03 \mathrm{~mm}$ in females. The identification points of $<100.99 \mathrm{~mm}$ and $>145.11 \mathrm{~mm}$ were deduced in males and females respectively, while the demarking points of $<90.54 \mathrm{~mm}$ in males and $>137.85 \mathrm{~mm}$ in females were obtained as shown in table (6).

Table (7): Measurements in degrees and statistical analysis of the subpubic angle in 500 pelvic plain X-ray films (250 males and 250 females)

\begin{tabular}{|c|c|c|c|c|c|}
\hline Sub-pubic angle & Male & Female & $\begin{array}{c}\text { Overall } \\
\text { mean } \\
\text { angle }\end{array}$ & $\mathrm{Z}$ value & P value \\
\hline Number & 250 & 250 & \multirow{9}{*}{$113.98^{\circ}$} & \multirow{9}{*}{-19.058} & \multirow{9}{*}{$\begin{array}{c}<0.001 * * \\
\text { (H.S) }\end{array}$} \\
\hline Mean value & $94.76^{\circ}$ & $133.20^{\circ}$ & & & \\
\hline Actual range & $67.0^{\circ}-119.0^{\circ}$ & $100.0^{\circ}-155.0^{\circ}$ & & & \\
\hline Standard deviation (SD) & 11.99 & 10.68 & & & \\
\hline Identification point (IP) & $<100.0^{\circ}$ & $>119.0^{\circ}$ & & & \\
\hline Percentage identification point & $59.6 \%$ & $85.6 \%$ & & & \\
\hline Calculated range (mean $\pm 3 \mathrm{SD}$ ) & $58.79^{\circ}-130.73^{\circ}$ & $101.16^{\circ}-165.24^{\circ}$ & & & \\
\hline Demarking point (DP) & $<101.16^{\circ}$ & $>130.73^{\circ}$ & & & \\
\hline Percentage demarking point & $66.4 \%$ & $58.4 \%$ & & & \\
\hline
\end{tabular}

(N.B.): H.S means: Highly significant. Overall mean angle means: The race was assigned from the overall mean for this racial group. Z. value means: Statistical comparison between males and females (Z. test). 

Table (7) showed that the subpubic angle had a greater mean value in females than in males with a highly significant difference $(\mathrm{p}<0.001)$. The overall mean angle in Egyptians in the present study was $113.98^{\circ}$. The range varied from $67.0^{\circ}-119.0^{\circ}$ in males with a mean value of $94.76^{\circ} \pm 11.99$ and from $100.0^{\circ}-$ $155.0^{\circ}$ in females with a mean value of $133.20^{\circ} \pm$ 10.68 . The identification points was $<100.0^{\circ}$ for males and $>119.0^{\circ}$ for females. The demarking points of $<$ $101.16^{\circ}$ is males and assigned sex accurately to $59.6 \%$ and $>130.73^{\circ}$ in females and could ascertain sex to about $85.6 \%$ of the Egyptian population in the present study.

\section{DISCUSSION}

In the present study, the pelvic bone has important differences in sex differentiation. The radiographic method was used in the present study. The ratio between the points were also measured, due to differences in the magnification of radiological films and the implementation of the size of radiographs with the actual size of the bone, in addition to the measurement of the absolute distances between points. Previous Egyptian studies have been conducted to identify sex from different skeletal elements as talus measurements ${ }^{(\mathbf{1 9})}$, hand bones ${ }^{(\mathbf{2 0})}$, maxillary sinus ${ }^{(\mathbf{} 1)}$, foot and patella (22) and first lumbar vertebra ${ }^{(23)}$. However, no Egyptian studies had been done on the pelvic bone to determine sex except Abdel Hameed $\boldsymbol{e t}$ al. ${ }^{(24)}$, which used plain x-ray films of the pelvis and dealt with one bony pelvic parameter and Mostafa $\boldsymbol{e t}$ al. ${ }^{(25)}$, which used Three-Dimensional Computed Tomography (3D-CT) of the pelvis and dealt with multible bony pelvic parameters but the present study dealt with more than one parameter by using plain $\mathrm{x}$ ray films.

\section{As regard sacral length}

The mean value of the sacral length was higher in males than in females with a highly significant difference between both sexes $(P<0.001)$. In the present study $0 \%$ of males and $0 \%$ of female's bones was identified by the demarking points. The present study showed that the identification points in males was $<78 \mathrm{~mm}$ and that of females was $>120 \mathrm{~mm}$. The demarking points in males was $<64.62 \mathrm{~mm}$ and that of females was $>127.06 \mathrm{~mm}$. It was found that the result obtained of the present study is in agreement with the result of the study from Agra region by Mishra et al. (26) in that the mean value of the sacral length in males was $107.53 \pm 7.03 \mathrm{~mm}$ while the mean value of the sacral length in females was $90.58 \pm 4.42 \mathrm{~mm}$. The mean value of the sacral length for males sacra of that study was higher than that of the Egyptian males while the mean value of the sacral length for females sacra of that study was lower than that of the Egyptian females in the present study. In addition, in that study $71.6 \%$ of males' and $23.08 \%$ of females' bones were identified by the demarking points, which is in disagreement with the present study in which the identification of bone sex cannot be detected by the sacral length. The identification points for males of that study was $<84$ $\mathrm{mm}$ and that of females was $>122 \mathrm{~mm}$, which is higher than that of both sexes in the present study. The demarking points for males of that study were $>103.84$ $\mathrm{mm}$ and that of females were $<86.44 \mathrm{~mm}$, which differs from the present study in which the demarking points for males were $<64.62 \mathrm{~mm}$ and that of females were $>127.06 \mathrm{~mm}$.

It was found that the results obtained of the present study are in agreement with the results of the study from India by Sachdeva et $\boldsymbol{a l} .{ }^{(27)}$ in that the mean value sacral length in males of that study was $104.1 \pm$ $12.6 \mathrm{~mm}$, while the mean value of the sacral length in females of that study was $91.8 \pm 7.1 \mathrm{~mm}$. The mean value of the sacral length for males sacra of that study was higher than that of the Egyptian males while the mean value of the sacral length for females sacra of that study was lower than that of the Egyptian females in the present study. The mean value of the sacral length in that study was higher in males than in females with a significant difference between both sexes $(\mathrm{P}<0.005)$ which is in agreement with the present study but differed in that the statistical difference between both sexes was highly significant difference in the present study. The identification points for males of that study were $<83.1 \mathrm{~mm}$ and that of females was $>131.2 \mathrm{~mm}$, which is higher than that of both sexes in the present study. The demarking points for males of that study were $>113.1 \mathrm{~mm}$ and that of females were $<66.3 \mathrm{~mm}$, which differed from the present study in which the demarking points for males were $<64.62 \mathrm{~mm}$ and that of females were $>127.06 \mathrm{~mm}$.

It was found that the results obtained of the present study are in agreement with the results of the study from Eastern India by Mazumdar et al. ${ }^{(18)}$ in that the mean value of the sacral length in males of that study was $100.8 \pm 11.5 \mathrm{~mm}$ and that of females was $87.3 \pm 7.4 \mathrm{~mm}$. The mean value of the sacral length for male's sacra of that study was very close to the Egyptian males while the mean value of the sacral length for females of that study was lower than that of the Egyptian females in the present study. In that study $7.9 \%$ of males' and $0 \%$ of females' bones were identified by the demarking points which disagrees with the present study in which the identification of bone sex cannot be detected by the sacral length. The demarking points for males of that study were $>109.5$ $\mathrm{mm}$ and that of females were $<66.3 \mathrm{~mm}$, which differs from the present study in which the demarking points for males were $<64.62 \mathrm{~mm}$ and that of females were $>127.06 \mathrm{~mm}$.

\section{As regard sacral width}

The present study showed that the mean value of the sacral width in males was $113.51 \pm 8.97 \mathrm{~mm}$ while the mean value of the sacral width in females was $111.48 \pm 10.31 \mathrm{~mm}$. The mean value of the sacral width was higher in males than in females with a significant 
difference between both sexes $(\mathrm{P}<0.019)$. In the present study $0 \%$ of males' and $0 \%$ of females' bones were identified by the demarking points. The identification points in males were $<91 \mathrm{~mm}$ and that of females were $>135 \mathrm{~mm}$. The demarking points for males were $>142.41 \mathrm{~mm}$ and that of females were < $86.6 \mathrm{~mm}$. Our results are in agreement with the results of the study of Sachdeva et al. ${ }^{(27)}$ in that the mean value of the sacral width in males was $103.1 \pm 7.8 \mathrm{~mm}$ while in females it was $101.7 \pm 7 \mathrm{~mm}$. The mean value of the sacral width for both males and females sacra of that study was lower than that of both sexes in the present study. The mean value of the sacral width in that study was higher in males than in females with no significant difference between both sexes $(\mathrm{P}<0.612)$ which is in agreement with the present study except in the statistical difference between both sexes which was significant in the present study. The identification points for males of that study were $<95 \mathrm{~mm}$, which is higher than that of the Egyptian males and that of females were $>119 \mathrm{~mm}$, which is lower than that of the Egyptian females in the present study. The demarking points for males of that study were $>122.7 \mathrm{~mm}$ and that of females were $<79.7 \mathrm{~mm}$ which is lower than that of both sexes in the present study.

It was found that the results obtained of the present study are in agreement with the results of Maddikunta and Ravinder ${ }^{(28)}$ in that the mean value of the sacral width in males of that study was $104.2 \pm$ $6.98 \mathrm{~mm}$ while the mean value of the sacral width in females was $103.4 \pm 6.02 \mathrm{~mm}$. The mean value of the sacral width for both males' and females' sacra in that study is lower than that of both sexes in the present study. The mean value of the sacral width in that study was higher in males than in females with no significant difference between both sexes, which is in agreement with the present study except in the statistical difference between both sexes which was significant in the present study. In that study $0 \%$ of males' and $0 \%$ of females' bones were identified by the demarking points which is in agreement with the present study. The identification points for males of that study were < $94.40 \mathrm{~mm}$ which is higher than that of the Egyptian males and that of females were $>115.30 \mathrm{~mm}$ which is lower than that of the Egyptian females in the present study. The demarking points for males of that study were $>121.46 \mathrm{~mm}$ and that of females were $<83.26$ $\mathrm{mm}$, which is lower than that of both sexes in the present study.

It was found that the results obtained of the present study are in agreement with the results of the study of Kamal $\boldsymbol{e t}$ al. ${ }^{(29)}$ in that the mean value of the sacral width in males of that study was $104.63 \pm 6.41$ $\mathrm{mm}$ while the mean value of the sacral width in females was $102.77 \pm 6.57 \mathrm{~mm}$. The mean value of the sacral width for both males' and females' sacra in that study is lower than that of both sexes in the present study. The mean value of the sacral width in that study was higher in males than in females with a highly significant difference between both sexes, which is in agreement with the present study except in the statistical difference between both sexes which was significant in the present study. The identification points for males of that study were $<83.08 \mathrm{~mm}$ and that of females were $>117.38 \mathrm{~mm}$, which is lower than that of both sexes in the present study. The demarking points for males of that study were $>122.48 \mathrm{~mm}$ which is lower than that of the Egyptian males and that of females were $<85.4 \mathrm{~mm}$, which is very close to the Egyptian females in the present study.

\section{As regard sacral index}

The present study showed that the mean value of the sacral index in males was $113.61 \pm 8.08 \mathrm{~mm}$ while the mean value of the sacral index in females was $120.63 \pm 10.03 \mathrm{~mm}$. The mean value of the sacral index was higher in females than in males with a highly significant difference between both sexes $(\mathrm{P}<0.001)$. In the present study $0 \%$ of males' and $5.2 \%$ of females' bones was identified by the demarking points. The present study showed that the identification points in males were $<100.99 \mathrm{~mm}$ and that of females were $>145.11 \mathrm{~mm}$ while the demarking points for males were $<90.54 \mathrm{~mm}$ and that of females were $>137.85 \mathrm{~mm}$. It was found that our results are in agreement with the results of Sachdeva et al. ${ }^{(27)}$ in that the mean value of the sacral index in males was $100.24 \pm 12.54 \mathrm{~mm}$ while the mean value of the sacral index in females was $111.74 \pm 14.6 \mathrm{~mm}$. The mean value of the sacral index for both males' and females' sacra in that study is lower than that of both sexes in the present study. The mean value of the sacral index in that study was higher in females than in males with a significant difference between both sexes $(\mathrm{P}<0.016)$ which is in agreement with the present study except in the statistical difference between both sexes, which was highly significant in the present study. The identification points for males of that study was $<88.79 \mathrm{~mm}$ which is lower than that of the Egyptian males and that of females was $>149.56 \mathrm{~mm}$ which is higher than that of the Egyptian females in the present study. The demarking points for males of that study were $<67.94$ $\mathrm{mm}$ which is lower than that of the Egyptian males and that of females were $>137.86 \mathrm{~mm}$ which is very close to the Egyptian females in the present study.

It was found that the results of the present study are in agreement with the results of Patel $\boldsymbol{e t} \boldsymbol{a l}$. (30) in that the mean value of the sacral index in males was $97.61 \pm 8.48 \mathrm{~mm}$ while the mean value of the sacral index in females was $113.4 \pm 9.73 \mathrm{~mm}$. The mean value of the sacral index for both males and females sacra in that study was lower than that of both sexes in the present study. The mean value of the sacral index in that study was higher in females than in males with a highly significant difference between both sexes $(\mathrm{P}<0.001)$, which is in agreement with the present study. In that study $6.57 \%$ of males' and $12 \%$ of females' bones were identified by the demarking points which disagrees with the present study in which 
only $0 \%$ of males' and $5.2 \%$ of females' bones was identified by the demarking points.

The identification points for males of that study were $<93.01 \mathrm{~mm}$ and that of females were $>112.71 \mathrm{~mm}$ while the demarking points for males of that study were $<84.21 \mathrm{~mm}$ and that of females were $>123.05 \mathrm{~mm}$, which was lower than that of both sexes in the present study.

\section{As regards subpubic angle}

The present study showed that the mean value of the subpubic angle in males was $94.76 \pm 11.99^{\circ}$ while the mean value of the subpubic angle in females was $133.20 \pm 10.68^{\circ}$. The mean value of the subpubic angle was higher in females than in males with a highly significant difference between both sexes $(\mathrm{P}<0.001)$. In the present study $66.4 \%$ of males' and $58.4 \%$ of females' bones were identified by the demarking points. Besides, the present study showed that, the identification points for males were $<100.0^{\circ}$ and that of females were $>119.0^{\circ}$ while the demarking points for males were $<101.16^{\circ}$ and that of females were $>130.73^{\circ}$. Our results are in agreement with the results of Isaac et al. ${ }^{(31)}$ in that the mean value of the subpubic angle in males was $94.2 \pm 7.4^{\circ}$ while the mean value of the subpubic angle in females was $117.1 \pm 11.3^{\circ}$. The mean value of the subpubic angle for males in that study is very close to the Egyptian males while the mean value of the subpubic angle for females in that study is lower than that of the Egyptian females in the present study. The mean value of the subpubic angles in that study was higher in females than in males with a highly significant difference between both sexes $(\mathrm{P}<$ 0.001 ), which is in agreement with the present study. The identification points for males of that study were < $96^{\circ}$ and that of females were $>114^{\circ}$ while the demarking points for males of that study were $<83.2^{\circ}$ and that of females were $>116.4^{\circ}$, which is lower than that of both sexes in the present study.

The result of the present study is in agreement with the results of the study from Egypt by Abdel Hameed et $\boldsymbol{a l} .{ }^{(24)}$ in that the mean value of the subpubic angle in males of that study was $102.31 \pm$ $12.50^{\circ}$ while the mean value of the subpubic angle in females was $143.28 \pm 15.82^{\circ}$. The mean value of the subpubic angles for both males and females in that study was higher than that of both sexes in the present study. In that study $74 \%$ of males' and $86.5 \%$ of females' bones were identified by the demarking points, which is in agreement with the present study. The identification points for males of that study were < $96^{\circ}$, which is lower than that of males in the present study and that of females were $>126^{\circ}$ which is higher than that of females in the present study. The demarking points for males of that study were $<111.64^{\circ}$, which is higher than that of males in the present study and that of females were $>127.31^{\circ}$, which is lower than that of females in the present study.
The present study is in agreement with the results of Sachdeva et al. ${ }^{(27)}$ in that the mean value of the subpubic angle in males was $59.05 \pm 7.11^{\circ}$, while the mean value of the subpubic angle in females was $75.60 \pm 9.81^{\circ}$. The mean value of the subpubic angles for both males and females in that study is lower than that of both sexes in the present study. The mean value of the subpubic angles in that study was higher in females than in males with a highly significant difference between both sexes $(\mathrm{P}<0.001)$ which is in agreement with the present study. The identification points for males of that study were $<57^{\circ}$ and that of females were $>75^{\circ}$, which is lower than that of both sexes in the present study. The demarking points for males of that study were $<46.17^{\circ}$ and that of females were $>80.38^{\circ}$, which is lower than that of both sexes in the present study.

In addition, the results of the present study are in agreement with the study of the Anatolian Caucasians by Karakas et al. ${ }^{(32)}$ in that the mean value of the subpubic angle in males of their study was 65.9 $\pm 7.2^{\circ}$, while the mean value of the subpubic angle in females was $82.6 \pm 7.7^{\circ}$. The mean values of the subpubic angles for both males and females in that study are lower than that of both sexes in the present study.

\section{The results of the present study showed the following}

Statistically significant increase in the length of sacrum in males compared to females $(100.06 \pm 9.00$ $\mathrm{mm}$ and $93.00 \pm 9.46 \mathrm{~mm}$ successively). There was a statistically significant increase in the width of sacrum in females than in males $(113.51 \pm 8.97 \mathrm{~mm}$ and 111.48 $\pm 10.31 \mathrm{~mm}$ successively). Besides, It was found a statistically significant increase in the sacral index in females than males (113.61 $\pm 8.08 \mathrm{~mm}$ and $120.63 \pm 10.03 \mathrm{~mm}$ successively). In addition, It has been found a statistically significant increase in the subpubic angles in females than males $\left(94.76 \pm 11.99^{\circ}\right.$ and $133.20 \pm 10.68^{\circ}$ successively).

\section{CONCLUSIONS}

The results of this study concluded that:

(1) The present study concluded that the subpubic angle is the best criterion for sex determination of pelvis. It was found that $66.4 \%$ of males' bones and $58.4 \%$ of females' bones could be identified using the subpubic angle alone.

(2) Other parameters studied like ventral straight length, maximum breadth and sacral index were less significant for sex determination of sacrum.

(3) However not a single parameter could identify $100 \%$ of the bones. Hence it could be concluded that for determination of sex of sacrum, maximum number of parameters should be taken into consideration to attain the $100 \%$ accuracy of results. 
(4) The subpubic angle in a sector of the Egyptian population showed a high accuracy rate for sex determination with high racial variability that allows its use in medicolegal identification of sex and race of unknown skeletal remains.

(5) Continuation of such studies in a defined geographic area over a period of time will definitely help in establishing the anthropometric standards.

(6) Such studies will be also useful to observe the changing trends if any, in the metric measurements which is influenced by environmental factors, socioeconomic factors, physical stress and genetic factors.

\section{RECOMMENDATIONS}

The following recommendations must be implemented:

1- Pay attention about recording and documentation of sacral index and subpubic angle measurements in the hospitals's archives which help the researchers to perform statistical studies about the determination of sex from pelvic bones in the various governorates of Egypt.

2- $\quad$ More elaborated studies should be done to study the sacral index and subpubic angle measurements in various governorates of Egypt, which help the authorities to develop a suitable strategy for determination of sex from pelvic bones especialy in mass disasters, e.g. in cases of train accidents, arsons, ship drowning, aeroplane crashes and other conditions associated with mutilation of human bodies or in case of missed persons.

3- $\quad$ Sample size should be as large as possible.

4- $\quad$ Future studies should determine the role of age in such research.

5- $\quad$ Need to establishment seminars and workshops about the different methods to determin sex and age from human skletal remains for all forensic medicine department physcians under the supervision of staff members specialized in forensic medicine.

6- Such studies should be done in the future by cooperation with the anatomy department of the Faculties of Medicine of the Egyptian Universities.

\section{REFERENCES}

1. Franklin D, O'Higgins P, Oxnard CE et al. (2008): Discriminant function sexing of the mandible of Indigenous South Africans. Forensic. Sci. Int., 179 (1): 15.

2. Laster WS, Ludlow JB, Bailey LJ et al. (2005): Accuracy of measurements of mandibular anatomy and prediction of asymmetry in panoramic radiographic images. Dentomaxillofac. Radiol., 34 (6): 343-9.
3. Kieser JA (1990): Human adult odontometrics: Sexual dimorphism in tooth size. Cambridge University Press Chap. 6, Pp: 63-73.

4. Kothapalli J, Velichety SD, Desai V et al. (2012): Morphometric study of sexual dimorphism in adult sacra of south Indian population. Int. J. Bio. Med. Res.,3 (3): 2076-81.

5. Reddy VM, Saxena S, Bansal $P$ (2008): Mandibular canine index as a sex determinant: A study on the population of western Uttar Pradesh. J. Oral Maxillofac. Pathol., 12 (2): 56-9.

6. Saini V, Srivastava R, Rai RK et al. (2011): Mandibular ramus: An indicator for sex in fragmentary mandible. J. Forensic Sci., 56 (1): S13-6.

7. Veyre-Goulet SA, Mercier C, Robin O et al. (2008): Recent human sexual dimorphism study using cephalometric plots on lateral teleradiography and discriminant function analysis. J. Forensic Sci., 53 (4): 786-9.

8. Kranioti EF, García-Donas JG, Langstaff H (2014): Sex estimation of the Greek mandible with the aid of discriminant function analysis and posterior probabilities. Romanian J. Leg. Med., 22101(101): 101-104.

9. Sinnatamby CS (2011): Lower limb. In: Last's Anatomy: Regional And Applied. 12 ${ }^{\text {th }}$ Ed. Sinnatamby, C. S. (ed.). Churchill, Livingstone. Elsevier., Pp: 268- 72.

10. Cheng JS, Song JK (2003): Anatomy of the Sacrum. Neurosurg Focus, 15 (2): 1-4.

11. Arora AK, Gupta P, Mahajan S et al. (2010): Significance of sacral index in estimation of sex in sacra of cadavers in Punjab. J. Indian Acad. Forensic Med., 32 (2): 104-7.

12. Klepinger LL (2006): Assignment of sex. In: Fundamentals of Forensic Anthropology. John Wiley \& Sons Inc., Pp: 25-41.

13. Di Vella G, Campobasso CP, Dragone M et al. (1994): Skeletal sex determination by scapular measurements. Boll. Soc. Ital. Biol. Sper., 70 (12): 299-305.

14.Singh S, Bhargava D, Deshpande A (2013): Dental orthopantomogram biometrics system for human identification. J. Forensic Leg. Med., 20 (5): 399-401.

15. Wilder HH (1920): The pelvic skeleton including hipgirdle and sacrum (Part I: Osteometry, the measurement of the bones). In: A laboratory manual of anthropometry. P. Blakistons sons \& Co., Part I., Pp: 114-119.

16.Davivongs V (1963): The pelvic girdle of the Australian aborigines-sex difference and sex determination. Am. J. Phys. Anthropol., 21 (4): 443-55.

17. Flander LB (1980): Univariate and Multivariate Method for sexing the sacrum. Am. J. Phys. Anthropol., 49 (1): 103-10.

18. Mazumdar S, Ray A, Mazumdar A et al. (2012): Sexual dimorphism and regional difference in size of sacrum: A study in Eastern India. Al Ameen J. Med. Sci., 5 (3): 298 $-307$.

19.Abdel Aleem SA, Abd-elhameed M, Ewis AA (2012): Talus measurements as a diagnostic tool for sexual dimorphism in Egyptian population. J. Forensic Leg. Med., 19 (2): 70-6.

20.Eshak GA, Ahmed HM, Abdel Gawad EA (2011): Gender determination from hand bones length and volume using multidetector computed tomography: a study in Egyptian people. J. Forensic Leg. Med., 18 (6): 246-52.

21. Amin MF, Hassan EI (2012): Sex identification in Egyptian population using multidetector computed 
tomography of the maxillary sinus. J. Forensic Leg. Med., 19 (2): 65-9.

22. Abdel Moneim WM, Abdel Hady RH, Abdel Maaboud RM et al. (2008): Identification of sex depending on radiological examination of foot and patella. Am. J. Forensic Med. Pathol., 29 (2): 136-40.

23.Badr El Dine FMM, El Shafei MM (2015): Sex determination using anthropometric measurements from multi-slice computed tomography of the 12th thoracic and the first lumbar vertebrae among adult Egyptians. Egyptian J. Forensic Sci., 5 (3): 82-89.

24. Abdel Hameed SY, Mohamed AA, Thabet HZ (2009): Determination of sub-pubic angle in Egyptian population. Mansoura J. Forensic Med. Clin. Toxicol., 17 (1): 41-53.

25. Mostafa EM, Dessouki SK, Hashish RK et al. (2016): Adult Sex Identification Using Three-Dimensional Computed Tomography (3D-CT) of the Pelvis: A Study Among a Sample of the Egyptian Population. Arab J. Forensic Sci. Forensic Med., 1 (3): 278-88.

26. Mishra SR, Singh PJ, Agrawal AK et al. (2003): Identification of sex of sacrum of Agra region. J. Anat. Soc. India, 52 (3): 132-6.
27.Sachdeva K, Singla RK, Kalsey G et al. (2011): Role of sacrum in sexual dimorphism - A morphometric study. J. Indian Acad. Forensic Med., 33 (3): 206-10.

28. Maddikunta V, Ravinder M (2014): Morphometric study of sacrum in sex determination in Telengana region people. Int. J. Res. Med. Sci., 2 (1): 164-74.

29. Kamal AM, Ara S, Hoque M et al. (2013): Significance of sacral index in estimation of sex in sacra of cadavers in Bangladesh. Bangladesh J. Anat., 11 (1): 11-14.

30.Patel S, Nigam M, Mishra P et al. (2014): A Study of sacral index and its interpretation in sex determination in Madhya Pradesh. J. Indian Acad. Forensic Med., 36 (2): 146-9.

31.Isaac UE, Ekanem TB, Igiri AO (2014): Gender differentiation in the adult human sacrum and the subpubic angle among indigenes of Cross River and Akwa Ibom states of Nigeria using radiographic films. Anat. J. Africa, 3 (1): 294- 307.

32. Karakas HM, Harma A, Alicioglu B (2013): The subpubic angle in sex determination: anthropometric measurements and analyses on Anatolian Caucasians using multidetector computed tomography datasets. J. Forensic Leg. Med., 20 (8): 1004-9. 